- Kết quả thay khớp: $84 \%$ tốt, 12\% khá

Phẫu thuật thay khớp háng bán điều trị gãy LMCXĐ là một giải pháp tốt cho người già, gãy LMCXĐ loai $A_{1}, A_{2}$.

\section{TÀI LIỆU THAM KHẢO}

1. Merle d'Aubigné R. (1970), "Cotation chiffrée de la fonction de la hanche". Rev Chir Ortho Reparatrice Appar Mot, 56 (5), pp 481-86.

2. Nguyệ̂n Mạnh Khánh, Đoàn Việt Quân, Nguyễn Xuần Thùy "Thay khớp háng bán phần ở bệnh nhân gãy liên mấu chuyển không vững" Tạp chí chấn thương chỉnh hình việt nam số $1-2012$, tr 39-44.

3. Phí Mạnh Công (2009). " Đánh giá kết quả điều trị gãy liên mấu chuyển xương đưi ở người trên 70 tuối bằng kết hợp xương nẹp vít động tại bệnh viện Xanh pôn và bệnh viện 198". Luận văn thạc sĩ $y$ hoc, tr 40-41.

4. Hoàng Thế Hùng (2013). "Đánh giá kết quả điêu tri gãy liên mấu chuyển xương đùi ở người cao tuổi bằng thay khớp háng bán phần bipolar". Luận văn thạc sỹ y học, học viện quân y, tr 50-51.

5. Sancheti K. H., Sancheti P. K., Shyam A. K., Patil S., Dhariwal Q., Joshi R., (2010), "Primary hemiarthroplasty for unstable osteoporotic intertrochanteric fracture in the elderly, a retrospective case series", Indian journal orthropaedic, 44, 428-434.

6. Hong-Man Cho, MD, Seung-Ryul Lee, MD... "Standard Type Cemented Hemiarthroplasty with Double Loop and Tension Band Wiring for Unstable Intertrochanteric Fractures in the Elderly" J Korean Hip Soc 22(2): 159-165, 2010

\title{
SẢN XUẤT THUỐC BẰNG CÔNG NGHÊ IN 3D FDM PHẦN 3: ỨNG DỤNG CÔNG NGHÊ IN 3D FDM TRONG LĨNH VỰC DƯợC PHẨM VÀ NHỮNG THÁCH THỨC
}

\author{
Lê Thị Thu Trang*, Trần Thị Hải Yến*, Võ Quốc Ánh*
}

\section{TÓM TẮT}

In 3D FDM là công nghê bồi đắp từng lớp để tạo thành cấu trúc chi tiết 3 chiều của vật thể với độ chính xác cao. Công nghê mới này mở ra cớ hội sản xuất các thuốc cá nhân hóa hướng tới người bệnh là trung tâm, phục vu nhu cầu điều trị riêng theo khả năng đáp ứng của mổi người bệnh. Đồng thời, công nghệ này cho phép sản xuất các dạng thuốc cấu trúc phức tạp thuốc đa thành phần, hệ nổi, dạng thuốc có kiểm soát giải phóng... Tuy có nhiều tiềm năng, song công nghệ in 3D cũ̃ng gặp phải không ít thách thức khi triển khai thực tiển. Có thể kể đến đó là: khó khăn trong việc nâng quy mô sản xuất, đảm bảo chất lượng và những vấn đề liên quan bản quyền, thủ tục pháp lỳ.

Từ khóa: Công nghệ in 3D, thuốc in 3D, cá nhân hóa điều trị, thuốc kiểm soát giải phóng.

\section{SUMMARY}

\section{OPPORTUNITIES AND CHALLENGES OF FUSED \\ DEPOSITION MODELING 3D PRINTING TECHNOLOGY IN PHARMACEUTICAL FORMULATION DEVELOPMENT}

Fused deposition modeling (FDM) is currently the most popular additive manufacturing technology owing to its flexibility, low cost and ease of use. This technology can fabricate complex objects as well as flexibly customize dosage forms satisfying treatment

*Trường đại học Dược Hà Nội

Chịu trách nhiệm chính: Võ Quốc Ánh

Email: anhvq@hup.edu.vn

Ngày nhận bài: 12.5 .2021

Ngày phản biện khoa họ: 2.7.2021

Ngày duyệt bài: 13.7.2021 needs of patients. Numerous polymer excipients have been studied that offer a wide range of choices for various pharmaceutical dosage forms such as control release, multi API loaded pills, intragastric floating drug delivery systems. However, this emerging technology also faces many challenges related to print quality issues, intellectual property and lack of regulatory guidelines when it comes to the industry.

Keywords: Three-dimension (3D) printing, 3D printed drugs, fused deposition modeling, material extrusion.

\section{I. ĐẶT VẤN ĐỀ}

Ngày nay, hầu hết các thuốc được sản xuất công nghiệp với quy mô lớn và đưa vào sử dụng điều trị đại trà. Thành phần, liều lượng thuốc được tính toán và thiết kế để phù hợp cho sô đông bệnh nhân. Phương pháp "một liều dùng cho tất cả" này gặp phải một số hạn chế về hiệu quả điều trị do sự khác nhau về giới tính, cẩn nặng, đặc điểm di truyền, khả năng chuyển hóa thuốc, môi trường sông, thói quen sinh hoạt giữa những người/nhóm người bệnh. Cùng một chế phẩm thuốc sẽ cho kết quả tốt trên bệnh nhân này, nhưng sẽ không cho kết quả ở bệnh nhân kia, thậm chí gây độc cho vài bệnh nhân khác. Để khắc phục hạn chế đó, "cá nhân hóa điều trị" (personalized treatment) được coi là phương pháp lý tưởng bởi nó lấy cá thể người bệnh làm trung tâm, hướng tới mục tiêu người nào thuốc nấy.

Trong những năm gần đây, sự phát triển khoa học kỹ thuật cùng với công nghệ in 3D đã mở ra cơ hội sản xuất thuốc theo nhu cầu điều 
trị, dược phẩm được bào chế dựa trên kết quả đáp ứng của từng người bệnh. Trong các kỹ thuật in 3D ứng dụng trong lính vực Dược phẩm, kỹ thuật tạo mô hình bằng bồi đắp-liên kết (fused deposition modeling- FDM) được nghiên cứu nhiều nhất do tính đơn giản, tiết kiệm và phù hợp sản xuất dạng thuốc viên uống. Trong vòng 5 năm trở lại đây, ứng dụng kỹ thuật FDM trong nghiên cứu các dạng bào chế đã thu hút được sự quan tâm lớn và là một chủ đề nghiên cứu mang tính thời sự cao với số lượng nghiên cứu được công bố trên các tap chí tăng trên 20 lần. Tuy vậy, ở Việt Nam tính đến nay chưa có nghiên cứu nào và thông tin về công nghệ này còn rất hạn chế. Vì vậy chúng tôi viết bài tổng quan này nhằm cung cấp thêm thông tin về những ứng dụng tiêu biểu của FDM trong nghiên cứu thiết kế các dạng bào chế như thuốc cá nhân hóa, thuốc có cấu trúc phức tạp, thuốc có kiểm soát giải phóng. Đồng thời, bài viết cũng sẽ đề câp đến những thách thức của công nghêe này như vấn đề bản quyền, quản lý chất lượng, tuân thủ pháp chế dược, những hạn chế về mặt kỹ thuật và phạm vi áp dụng...

\section{NHỮNG ỨNG DỤNG CỦA KỸ THUÂTT IN 3D FDM TRONG NGÀNH DƯƠC}

2.1. Mô hình chăm sóc $y$ tế điên tử (digital medicine, electronic medicine). Vai trò của việc ứng dụng công nghệ số vào chăm sóc và quản lý sức khỏe con người ngày càng được khẳng định bằng những lợi ích mà nó có thể mang lại. Các thông tin như tiền sử bệnh tật, lịch sử điêu trị và can thiệp y tế, lịch sử thay đổi của các chỉ số sinh hóa, lịch sử đáp ứng thuốc cũng như các tác dụng bất lợi và biến chứng... của từng cá nhân sẽ được quản lý đầy đủ và toàn diện [1]. Những thông tin này không chỉ giúp bác sĩ nhanh chóng tiên lượng được tình trạng bệnh và xác định được hướng điêu trị phù hợp mà nó còn giúp dự đoán được các vấn đề y tế mà một cá nhân có thể gặp phải trong tương lai, để từ đó có những biện pháp phòng ngừa và chăm sóc y tế phù hợp ngay từ khi chưa có biểu hiện về bệnh.

Dựa trên bộ dữ liệu đầy đủ này, cùng với những chỉ số xét nghiệm và chẩn đoán, bác sĩ sẽ nhanh chóng đưa ra các yêu cầu về loai thuốc, liều lượng, thuốc phối hợp, yêu cầu về kiểm soát giải phóng của từng dược chất. Trong mô hình y tế số, các thông tin này được chuyển đến khoa dược bệnh viện, hiệu thuốc hoặc cơ sở pha chế thuốc theo đơn đã được cấp phép. Tại những cơ sở này, các thuốc cá nhân hóa được thiết kế một cách chính xác và tức thì thông qua các thuật toán đã được xây dựng từ trước. Đầu ra của các thuật toán này là các thông số được chuyển thành các lệnh điều khiển hệ thống sản xuất các thuốc đã được kê đơn, trong đó máy in 3D đóng vai trò trung tâm của hệ thống này.

2.2. Thuốc cá nhẩn hóa. Sự đáp ứng của người bệnh đối với một loại thuốc có thể khác nhau, ngay cả khi sử dụng cùng liều lượng. Đó là do sự khác nhau về thể chất (cân nặng, tuổi tác) và khác nhau về dược động học (khả năng chuyển hóa, khả năng thải trừ, chức năng của các cơ quan) giữa các cá thể. Vì vậy, sử dụng liều lượng phù hợp đối với từng cá thể là điều cần thiết để đảm bảo độ an toàn và hiệu quả điều tri. Công nghê in 3D cho phép sản xuất các chế phẩm với liều lượng chính xác, đáp ứng nhu cầu riêng biệt của từng bệnh nhân. Thậm chí với sự linh hoạt, công nghệ này có thể đáp ứng được nhu cầu thay đổi về liều lượng, thành phần thuốc ở những giai đoạn điều trị khác nhau trên cùng một người bệnh.

2.3. Tác động thay đổi mô hình giải phóng dược chất. Một trong những ưu điểm của công nghệ in 3D FDM so với kỹ thuật sản xuất thuốc thông thường là nó có thể sản xuất chế phẩm đa dạng về kích thước, hình dạng chỉ bằng vài thao tác nhỏ với chuột máy tính. Với cấu trúc từ đơon giản đến phức tap, các chế phẩm in 3D cho phép điều khiển động học giải phóng dược chất theo yêu cầu điêu trị đối với từng bệnh nhân, từ giải phóng nhanh đến giải phóng kéo dài hay giải phóng ngắt nhịp.

Viên giải phóng kéo dài. Bằng cách thay đổi hình dáng viên thuốc (Hình 1f, g), Goyanes đã cải biến khả năng giải phóng của paracetamol. Kết quả cho thây thuốc trong viên hình cầu hoặc hình trụ sẽ được giải phóng chậm nhất ( $90 \%$ dược chất sau 12h). Trong khi đó, với cùng diện tích bề mặt, viên hình kim tự tháp cho phép dược chất giải phóng nhanh hơn rất nhiều (90\% dược chất dưới $2 \mathrm{~h}$ ) $[2,3]$.

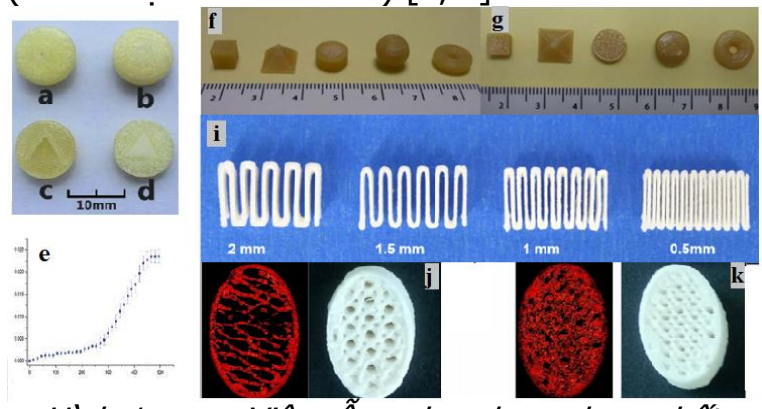

Hình 1: a, c: Viên rống chưa bơm dược chất; b,d: Viên chứa lớp dược chất hinh kim tự tháp; 
e: nồng độ paracetamol $(\mathrm{ng} / \mathrm{ml})$ giải phóng theo thơ gian; f,g: viên paracetamol với hinh dạng khác nhau; i: chế phẩm câu trúc bộ tản nhiệt; j,k: viên câu trúc tồ ong.

Bên cạnh khả năng kiểm soát giải phóng thuốc thồng qua hình dạng chế phẩm, công nghệ in 3D FDM còn cho phép điều khiển khả năng giải phóng bằng cách thay đổi độ dày lớp vỏ hoặc độ đặc rỗng của viên, điều mà khó có thể thực hiện với phương pháp sản xuất dược phẩm truyền thông. Giải phóng dược chất sẽ có xu hướng chậm đi với những viên có lớp vỏ dày hoặc những viên có độ đặc cao.

Một trong những thế mạnh lớn nhất của công nghệ in 3D FDM là tạo ra được các sản phẩm có cấu trúc phức tạp. Zhao và cộng sự đã bào chế thành công viên nén chứa kho dược chất hình kim tự tháp (Hình $1 \mathrm{a}, \mathrm{b}, \mathrm{c}, \mathrm{d}$ ). Nằm trong "kho" kim tự tháp, dược chất ở bốn góc cạnh được giải phóng trước, sau đó đến những vùng lân cận, tạo ra mô hình giải phóng hàm convex (hình 1e). Mô hình giải phóng này đặc biệt hữu ích đối với thuốc điều trị một số bệnh như tăng huyết áp, khi mà bệnh nhân có thể uống thuốc từ buổi tối và thuốc sẽ phát huy tác dụng vào sáng sớm ngày hôm sau [3].

Viên giải phóng nhanh. Isreb và cộng sự đã nghiên cứu bào chế viên giải phóng nhanh với cấu trúc gấp nếp (Hình 1i). Cấu trúc này giúp tăng tỷ lệ diện tích bề mặt/khối lượng viên gấp 7-8 lần so với viên nén truyền thống. Từ đó giúp tăng tốc độ giải phóng dược chất [4]. Tương tự, Fanous cũng đã nghiên cứu bào chế viên caffein cấu trúc tổ ong (Hình $1 j, k$ ), giúp dược chất giải phóng hòa toàn trong vòng 20 phút [3].

Giải phóng muộn (delayed release) và giải phóng theo mô hình 2 pha (bimodal release).

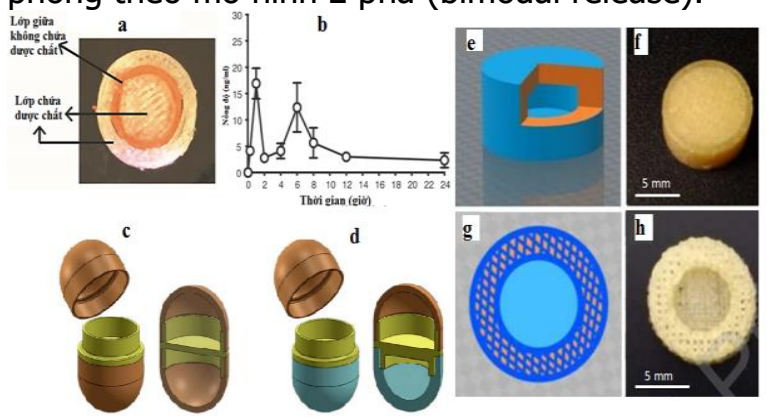

Hình 2: a: câuu trúc viên ngắt nhịp, 3 lớp; $b$ : nồng độ diltiazem giải phóng theo thời gian; $c$, d: vỏ nang 2 ngăn với độ dày vó giống (c) hoặc khác nhau (d); $e, f, g$, h: viên nôi theo mô phỏng $(e, g)$ và thức tế $(f, h)$.

Kadry đã ứng dụng kỹ thuật in 3D FDM bào chế viên đa lớp (Hình 3a) với cấu trúc 2 lớp chứa dược chất, ngăn cách nhau bởi một lớp polymer không chứa dược chất. Kết quả thu được, diltiazem giải phóng trong 2 giờ đầu từ lớp bên ngoài. Sau đó ngắt quãng trong thời gian 2 giờ tiếp theo ( $\mathrm{t}=2$ - $4 \mathrm{~h})$ do lớp ở giữa không chứa dược chất. Cuối cùng dược chất tiếp tục được giải phóng ( $\mathrm{t}=4-8 \mathrm{~h}$ ) từ lớp trong cùng (Hình 2b) [3].

2.4. Viên đa thành phân. Thuốc đa thành phần làm tăng tính thuận tiện và giúp bệnh nhân tuân thủ phác đồ điều trị. So với viên sản xuất thông thường, viên đa thành phần được sản xuất bằng phương pháp in nhiều lớp theo công nghệ 3D không những giúp tách riêng dược chất tương $k y$, tăng độ ổn định dược chất, thay đổi liều cho từng dược chất theo mong muốn. Ngoài ra, những viên dạng này còn cho phép điều chỉnh mô hình giải phóng bằng cách thay đổi vị trí của các lớp. Maroni và cộng sự đã bào chể thành công vỏ viên nang 2 ngăn bằng công nghệ FDM (hình 2 c,d) có thể chứa đựng 2 loại dược chất tương ky với nhau hoặc 2 công thức khác nhau [3]. Christos và cộng sự đã nghiên cứu viên 2 lớp chứa 2 dược chất đ̛iêu trị bênh tiểu đường bằng công nghệ FDM với 2 sợi in chứa 2 dược chất được đưa riểng biệt vào đầu in kép để đảm bảo tách riêng hoàn toàn 2 dược chất. Cấu trúc này cho phép điều khiển glimepirid giải phóng nhanh, trong khi dược chất thứ 2metformin kiểm soát giải phóng kéo dài [5].

2.5. Viên nổi. Trên thực tế, một số dược chất có cửa sổ hấp thu rất hẹp ở phẩn trên của đường tiêu hóa. Đối với nhóm dược chất này, thời gan lưu giữ thuốc trong dạ dày là một trong những nhân tố chính quyết định sinh khả dụng của thuốc. Hệ nổi (hệ có tỷ trọng thấp) là một trong những giải pháp hiệu quả giúp làm tăng thời gian lưu thuốc ở dạ dày. Anh V.Q và cộng sự đã ứng dụng công nghệ in $3 \mathrm{D}$ và bào chế thành công viên cinnarizin hình trụ rỗng nổi trong dạ dày (Hình 2f). Lực nổi và khả năng giải phóng dược chất được điều chỉnh bằng cách thay độ rỗng trong lòng viên, độ dầy thành viên và độ dày đáy/nắp viên. Viên có khả năng nổi ngay lập tức trong môi trường mô phỏng dịch vị và lực nổi được duy trì gần như hằng định trong vòng $12 \mathrm{~h}$. Dược chất giải phóng từ dạng bào chế tuân theo mô hình giả động học bậc 0 và được kiểm soát từ $6 \mathrm{~h}$ đến trên $12 \mathrm{~h}$ [6].

\section{NHŨ̃NG THÁCH THỨC Vớl CÔNG NGHẸ IN 3D FDM}

Mặc dù in 3D là công nghệ mang nhiêu hứa hẹn cho công nghiệp Dược, đặc biệt trong lĩnh 
vực sản xuất thuốc cá nhân hóa và kiểm soát giải phóng. Công nghệ này cũng đối mặt với không ít những thách thức khi ứng dụng vào thức tiễn sản xuất thuốc. Các thách thức có thể kể đến gồm có: đảm bảo chất lượng sản phẩm, quy mô sản suất, các vấn đề về bản quyền và các trở ngại trong việc đăng ký thuốc.

3.1. Chất lượng sản phẩm. Một trong những vấn đề thường gặp đối với công nghệ in 3D FDM là sự phân hủy dược chất, tá dược trong quá trình đùn và in do tác động của nhiệt độ. Giải pháp cho vấn đề này là sử dụng polyme có nhiệt độ nóng chảy thấp hoặc thêm các chất hóa dẻo vào công thức để quá trình đùn/in có thể được tiến hành ở nhiệt độ phù hợp.

Bên canh độ ổn định về mặt hóa học, chất lượng về mặt hình thức thể hiện qua độ phân giải độ sắc nét của vật thể cũng rất được quan tâm. Trong các kỹ thuật in 3D, FDM có độ phân giải gần như thấp nhất. Để cải thiện độ phân giải của mẫu in 3D FDM có thể thay đổi kích thước đầu in. Thông thường đầu in càng nhỏ, viên thuốc được in sẽ có bề mặt càng mịn, sắc nét và gần với thiết kế. Tuy nhiên, đâu phun nhỏ sẽ làm giảm tốc độ và tăng thời gian in.

3.2. Tốc độ in và khả năng nâng quy mô sản xuất. Một trong nố lực của các nghiên cứu hiện nay là làm tăng tốc độ in $3 \mathrm{D}$, theo một số tài liệu thời gian để in một viên thuốc theo kỹ thuật FDM là khoảng 2-5 phút, chưa kể thời gian làm khô (nếu có) và thời gian phụ trợ khác. Thực tế là, dù cố gắng cải thiện thì năng suất của công nghệ in 3D này vẫn còn rất nhỏ so với phương pháp sản xuất công nghiệp truyền thống, đạt vài chục ngàn viên/phút. Có thể nói, công nghệ in 3D sẽ không thay thế hoàn toàn sản xuất công nghiêp. Tuy nhiên, khác với sản xuất truyền thống theo lô mẻ, FDM có thể phát triển theo mô hình sản xuất liên tục. Điêu này có thể tăng đáng kể công suất tổng thể của dây chuyền. Đồng thời, việc thiết kế nhiều máy in 3D hoạt động đông thời có thể tăng công suất lên nhiều lần và đáp ứng được yêu cầu về công suất sản xuất.

3.3. Vấn đề về bản quyền và trách nhiệm. Thuốc in 3D hướng tới phục vụ nhu cầu từng cá thể. Trong tương lai, dưới sự kiểm soát của nhân viên y tế, người bệnh có thể sử dụng máy in để sản xuất thuốc điều trị bệnh cho chính mình. Trong trường hợp này, khi công thức bào chế đã được công bố, việc giữ bản quyền cho công ty nghiên cứu sẽ là điêu không thể. Bên canh đó, vấn đề về quản lý thuốc, phân bổ trách nhiệm sẽ khó khăn hơn khi người bệnh tự in thuốc và cỗ tình làm trái phép hoặc trong quá trình vận hành máy, người bệnh gây sai sót dẫn đến những hậu quả nghiêm trọng

3.4. Vấn đề về tuân thủ pháp chế quy chế dược. Cho đến nay, Hoa Kỳ là nước đầu tiên và duy nhất trên thế giới đã cấp phép cho một thuốc được sản xuất bằng công nghệ in 3D. Kể từ sản phẩm đầu tiên được cấp phép từ năm 2015, đến nay chưa có thêm sản phẩm sản phẩm thứ hai nào dựa trên công nghệ in $3 \mathrm{D}$ được phê duyệt. Điều đó cho thấy hể thống pháp lý dược vẫn chưa sẵn sàng cho việc phê duyệt rộng rãi công nghệ này.

Công nghệ in 3D có thể được ứng dụng vào sản xuất thuốc chữa bệnh bằng một trong ba mô hình: sản xuất công nghiệp với số lượng lớn; bào chế tại các khoa dược bệnh viện và các hiệu thuốc được cấp phép; và bệnh nhân có thể tự bào chế tại nhà dựa trên sự chỉ định của bác sĩ. Nếu áp dụng theo mô hình thứ nhất có thể áp dụng tất cả các quy định hiện hành về sản xuất dược phẩm cho loại hình sản xuất này. Tuy nhiên ở 2 mô hình còn lại, để có thể ứng dụng rộng rãi công nghệ in $3 \mathrm{D}$, cần thiết phải xây dựng một hệ thống đầy đủ các quy định pháp lý liên quan đến việc chuẩn hóa thiết bị và phần mềm; kiểm soát chất lượng và chống nhiễm chéo; yêu cầu về cơ sở ha tầng và nhân sự; quản lý và tồn trữ thành phẩm; bán thành phẩm, phế phẩm..

Đứng trên góc độ quản lý, kiểm soát chất lượng sản phẩm và kiểm đinh thiết bi là hai điểm khác biê̂t nổi bật của mô hình sản xuất thuốc bằng in $3 \mathrm{D}$ so với mô hình truyền thống. Thứ nhất, trong quy trình in 3D có rất ít điểm có thể lấy mẫu để thực hiện kiểm soát chất lượng trong quá trình sản xuất. Điều đó đòi hỏi việc kiểm soát và đảm bảo chất lượng phải tiên tiến hơn so với công nghệ đương thời. Sự phát triển mạnh mẽ của công nghệ PAT (process analytical technology) kết hợp với ứng dụng quality by design có thể hiện thực hóa việc kiểm soát chất lượng theo thời gian thực, trực tiếp trên dây chuyền để đáp ứng được yêu cầu này của sản xuất thuốc bằng in 3D. Thứ 2 là, các máy in 3D được sản xuất rộng rãi từ rất nhiều nguồn khác nhau đặt ra thách thức lớn cần có các quy định pháp lý chặt chẽ về tiêu chuẩn hóa thiết bị, điêu chưa thực hiên được ở tất cả các nước trên thế giới. Thềm vào đó, sự tương thích và ổn định của phần mềm điều khiển với phần cứng là các máy in 3D cũng cần phải được thẩm định cẩn thận theo các quy định của nhà quản lý. Nhìn chung lại, tuy đã có nền tảng về pháp lý hỗ trợ ở 
các nước phương tây [7] [8] , nhưng vẫn cần xây dựng hệ thống các quy định, hướng dẫn ứng dụng việc ứng dụng công nghệ in $3 \mathrm{D}$ vào sản xuất thuốc chữa bệnh.

\section{KẾT LUÂ̂N}

Với tính chính xác và linh hoạt, công nghệ in 3D FDM mang lại nhiều hứa hẹn cho sự phát triển của nghành Dược theo hướng sản xuất thuốc cá nhân hóa, đáp ứng yêu cầu của từng người bệnh. Công nghệ này cho phép bào chế các dạng thuốc đa thành phần, dạng thuốc có cấu trúc đặc biệt và điều khiển động học giải phóng thuốc theo yêu cầu điều trị của từng người bệnh. Trong tương lai, thuốc có thể được sản xuất tại bệnh viện, nhà thuốc hoặc thậm chí tại nhà riêng của người bệnh. Tuy vậy, để hiện thực hóa điều này, cần có nhiều nghiên cứu nâng cấp công nghệ, chuẩn hóa thiết bị và ứng dụng các PATs trong kiểm soát chất lượng sản phẩm. Đồng thời, cũng cần phải có hệ thống đầy đủ các hướng dẫn, quy định pháp lý để điều chỉnh hoạt động sản xuất và thương mại thuốc sản xuất bằng công nghệ in $3 \mathrm{D}$.

\section{TÀI LIẸU THAM KHẢO}

1. Pacurariu, A.C., Straus, S.M., Trifiro, G.,
Schuemie, M.J., Gini, R., Herings, R. Mazzaglia, G., Picelli, G., Scotti, L., and Pedersen, L. (2015). Useful interplay between spontaneous ADR reports and electronic healthcare records in signal detection. Drug safety 38, 1201-1210.

2. Procopio, A.a.T., D. (2020). Opportunities and challenges of 3D-printed pharmaceutical dosage forms. In Drug Delivery Trends, 15-44.

3. Chen, G., Yihua, X., Kwok, P., \& Kang, L. (2020). "Pharmaceutical applications of 3D printing". Additive Manufacturing, , 101209.

4. Isreb, A., et al. (2019). "3D printed oral theophylline doses with innovative 'radiatorlike'design: Impact of polyethylene oxide (PEO) molecular weight.". International journal of pharmaceutics. 564, 98-105.

5. Gioumouxouzis, C.I., et al. (2018). "A $3 D$ printed bilayer oral solid dosage form combining metformin for prolonged and glimepiride for immediate drug delivery.". European Journal of Pharmaceutical Sciences, 120, 40-52.

6. Vo, A.Q., et al (2020). "Hot melt extrusion paired fused deposition modeling 3D printing to develop hydroxypropyl cellulose based floating tablets of cinnarizine." Carbohydrate Polymers, 246

7. Di Prima, M., Coburn, J., Hwang, D., Kelly, J., Khairuzzaman, A., and Ricles, L. (2016). Additively manufactured medical products-the FDA perspective. 3D printing in medicine 2, 1-6.

8. Khairuzzaman, A. (2018). Regulatory perspectives on 3D printing in pharmaceuticals. In 3D Printing of Pharmaceuticals. (Springer), pp. 215-236.

\section{ĐÁNH GIÁ KẾT QUẢ PHẪU THUÂT NỘI SOI HOÀN TOÀN NGOÀI PHÚC MAC (TEP) ĐĂT LƯớI NHÂN TAOO 3D ĐIỀU TRI THOÁT VỊ BẸN HAI BÊN Ở NGƯỜI LỚN}

\section{TÓM TẮT}

Mục tiêu: Đánh giá kết quả thuật phẫu thuật nội soi hoàn toàn ngoài phúc mac (Total Extraperitoneal TEP) đặt lưới nhân tạo 3D điều trị thoát vị bẹn hai bên ở người lớn. Đối tượng và phương pháp: Nghiên cứu mô tả 60 bệnh nhân (BN) trên 18 tuổi được chẩn đoán là thoát vị ben (TVB) hai bên và được điều trị bằng phẫu thuật nội soi TEP đặt lưới nhân tạo 3D tại Bênh viện Thanh Nhàn, từ tháng $01 / 2017$ đến tháng 11/2020. Kết quả: 60 BN với 63,3\% TVB trực tiếp, $36,7 \%$ gián tiếp. Thời gian đau sau mổ 2,2 ngày. Biến

*Bênh viện Thanh Nhàn

**Đại học Y Dước Hải Phòng

***Trung tâm PTTH - Bênh viên TW 108

Chịu trách nhiệm chính: Nguyễn Văn Phước

Email: drphuocbvtn@gmail.com

Ngày nhận bài: 12.5.2021

Ngày phản biên khoa hoc: 5.7.2021

Ngày duyệt bài: 14.7.2021

\author{
Nguyễn Văn Phước*, Hà Văn Quyết**, \\ Đào Quang Minh*, Vũ Ngọc Sơn***
}

chứng sớm $10,0 \%$. Thời gian nằm viện sau mổ trung bình 3,97 ngày. Thời gian trung bình 21,8 tháng, biến chứng đau mạn tính vùng bẹn bìu $1,8 \%$, không trường hớp nào tái phát. Kết luân: PTNS hoàn toàn ngoài phúc mạc đặt lưới nhân tạo 3D là phương pháp an toàn và hiệu quả trong điều trị thoát vị ben hai bên ở người lớn với tỷ lệ biến chứng và tái phát thấp.

\section{SUMMARY}

RESULTS OF LAPAROSCOPIC TOTALLY EXTRAPERITONEAL USING 3-DIMENSION MESH TO TREAT BILATERAL INGUINAL HERNIA IN ADULTS

Objective: This study aimed to evaluate the results of laparoscopic totally extraperitoneal (TEP) using 3D mesh to treat bilateral inguinal hernia in adults. Methods: Descriptive study 60 patients with bilateral inguinal hernias undergoing laparoscopic TEP surgery using 3D mesh at Thanh Nhan Hospital from January 2017 to November 2020. Results: Of 60 